
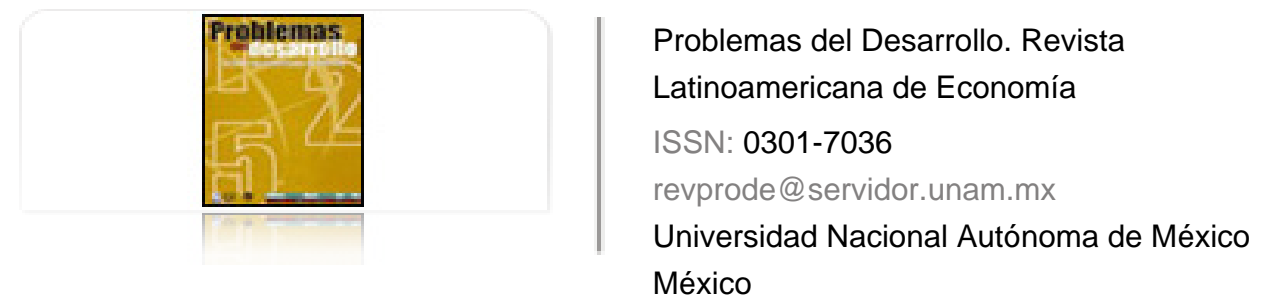

Rodríguez Nava, Abigail; Venegas Martínez, Francisco INDICADORES DE RENTABILIDAD Y EFICIENCIA OPERATIVA DE LA BANCA COMERCIAL EN MÉXICO

Problemas del Desarrollo. Revista Latinoamericana de Economía, vol. 41, núm. 161, abril-junio, 2010, pp. $165-191$

Universidad Nacional Autónoma de México

Distrito Federal, México

Disponible en: http://www.redalyc.org/articulo.oa?id=11820105007

Cómo citar el artículo

- Número completo

- Más información del artículo

Página de la revista en redalyc.org

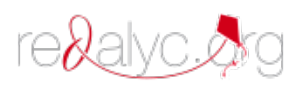

Sistema de Información Científica

Red de Revistas Científicas de América Latina, el Caribe, España y Portugal Proyecto académico sin fines de lucro, desarrollado bajo la iniciativa de acceso abierto 


\title{
INDICADORES DE RENTABILIDAD Y EFICIENCIA OPERATIVA DE LA BANCA COMERCIAL EN MÉXICO
}

\author{
Abigail Rodríguez Nava* \\ Francisco Venegas Martínez**
}

Fecha de recepción: 22 de diciembre de 2009. Fecha de aceptación: 4 de mayo de 2010.

\section{Resumen}

Se analiza la estructura de la banca comercial en México y los principales indicadores de rentabilidad y eficiencia operativa en los años recientes. Se pretende precisar cuáles son los determinantes de los rendimientos y de las condiciones de operación, así como la vinculación entre éstos; en especial se evalúan los factores de tamaño y concentración del mercado, apalancamiento, márgenes por intereses, márgenes por operación, y utilidades netas. Los resultados muestran diferencias significativas entre los bancos de acuerdo con su tamaño: la banca comercial exhibe una evolución no homogénea. Si bien los bancos que generan más utilidades son los bancos grandes y los medianos, los primeros son eficientes por sus amplios márgenes netos de intereses y margen de operación, mientras que los bancos medianos derivan sus utilidades de su rotación de activos y elevado apalancamiento. El documento expone también los cambios ocurridos en la estructura del sector como consecuencia de la liberalización financiera, privatización y entrada del capital extranjero que ocurrió en la década de los noventa.

Palabras clave: banca comercial, razones de rentabilidad, eficiencia operativa, economía mexicana.

Clasificación JEL: G20, G21.

* Profesora del Departamento de Producción Económica, Universidad Autónoma MetropolitanaXochimilco. Correo electrónico: arnava@correo.xoc.uam.mx

** Profesor de la Escuela Superior de Economía, Instituto Politécnico Nacional. Correo electrónico: fvenegas1111@yahoo.com.mx 


\section{Abstract}

We analyze the structure of the commercial banks in Mexico and the main indicators of profitability and operating efficiency in recent years. The aim is to clarify what are the determinants of the yields and operating conditions, as well as the links between them. In particular, we assess factors of market size and concentration, leverage, interest rate margins, operating margins, and net earnings. The results show significant differences between the banks according to their size: the commercial banks exhibit uneven growth. While the banks that generate the biggest earnings are the large and medium-sized ones, the first are efficient due to their wide net interest margins and operating margins, while the medium-sized banks derive their earnings from the turnover of their assets and high leverage. We also consider the changes that have occurred in the structure of this sector as a result of the financial liberalization, privatization and inflow of foreign capital that took place during the 1990s.

Keywords: commercial banks, profitability, operating efficiency.

\section{Résumé}

Il est procédé à l'analyse de la structure de la banque commerciale au Mexique et les principaux indicateurs de rentabilité et de performance opérative ces dernières années. Ce travail prétend préciser quels sont les facteurs qui déterminent les rendements et les conditions d'opération, ainsi que le lien qui unit ceux-ci; on y évalue notamment les facteurs de taille et concentration du marché, appel d'épargne, marges issues des intérêts, marges issues de l'opération et utilités nettes. Les résultats indiquent des différences significatives entre les banques selon leur taille: la banque commerciale fait montre d'une évolution hétérogène. S'il est vrai que les banques qui génèrent le plus d'utilités sont les grandes et les moyennes, les premières sont performantes pour leur ample marge nette issue des intérêts et leur marge d'opération, tandis que les moyennes tirent leurs utilités de leur rotation d'actifs et d'un intense appel d'épargne. Cette étude expose aussi les changements survenus dans la structure du secteur par suite de la libéralisation financière, de la privatisation et de l'entrée du capital étranger au cours des années 90.

Mots clés: banque commerciale, raisons de rentabilité, performance opérative.

\section{Resumo}

Analisa-se a estrutura do sistema bancário comercial no México e os principais indicadores de rentabilidade e eficiência operativa nos anos recentes. Pretende-se especificar quais são os determinantes dos rendimentos e das condições de operação, bem como a vinculação entre os mesmos; em especial avalíam-se os fatores de tamanho e concentração do mercado, alavancamento, margens por juros, margens por operação, e utilidades líquidas. Os resultados mostran diferenças significativas entre os bancos de acordo com o seu tamanho: o sistema bancário comercial exibe uma evolução não homogênea. Se bem que os bancos que geram mais utilidades são os grandes e os médios, os primeiros são eficientes por suas amplas margens líquidas de juros e a margem de operação, enquanto que os médios derivam suas utilidades de sua rotação de ativos e elevado alavancamento. Expõem-se também as mudanças ocurridas na estrutura do setor como consequência da liberalização financeira, privatização e entrada de capital estrangeiro que ocurreu na década de 1990.

Palavras-chave: sistema bancário comercial, razões de rentabilidade, eficiência operativa. 


\section{Introducción}

ntre los tópicos esenciales que explican el funcionamiento del sistema financiero, se encuentra el análisis de las condiciones de operación de las institu-

ciones financieras, en particular de la banca comercial. Numerosos estudios se han dedicado a investigar el funcionamiento, la estructura del balance financiero, los tipos de transacciones y las condiciones de rentabilidad, pero en su mayoría se enfocan en la banca internacional y más aún en la banca estadounidense.

En el caso de México y de Latinoamérica, las investigaciones recientes muestran la situación global de la banca; por lo general, la rentabilidad se asocia con el amplio diferencial entre las tasas activas y pasivas con que operan los bancos, mientras la eficiencia se vincula con la capacidad del sector para apoyar las actividades productivas.

El propósito de esta investigación es mostrar cómo ha sido la evolución de los indicadores de concentración, rentabilidad y eficiencia operativa de la banca comercial con

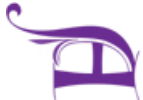
actividades en México. En especial, la evolución de la rentabilidad y el apalancamiento, distinguiendo entre los diferentes bancos de acuerdo con su tamaño; asimismo, se muestran las vinculaciones entre las razones financieras estimadas. Hasta la fecha, las investigaciones dedicadas a la banca la han analizado en su conjunto, como si todas las instituciones tuvieran el mismo comportamiento, aunque no necesariamente es así; he aquí la relevancia de esta investigación, que aprovecha la información disponible sobre los estados financieros de cada banco entre 2002 y 2009 para diferenciar las instituciones por su tamaño y estudiarlas de acuerdo con este criterio.

Precisamente uno de los principales resultados de la investigación es la evidencia de diferentes fuentes de la rentabilidad entre los bancos: los bancos grandes obtienen resultados muy favorables en el margen neto de operación y en el margen neto por intereses, mientras que los bancos medianos y pequeños generan rendimientos a partir de la elevada utilización de sus activos y del considerable apalancamiento.

En la siguiente sección del documento, se presenta un breve panorama de los estudios previos, teóricos y empíricos, que han examinado las características de operación de las instituciones bancarias; a continuación se analizan las condiciones de estructura y concentración del sector; también, la rentabilidad y eficiencia operativa de la banca comercial en México a través del cálculo de índices de concentración y de las razones financieras para cada banco; asimismo, mediante regresiones de datos en panel, se busca precisar los determinantes de la rentabilidad en cada grupo de bancos; por último, se presentan las conclusiones. 


\section{Estudios previos de la banca comercial}

En el estudio de la banca comercial se han delineado varias líneas de investigación, entre ellas: actividades y funciones de intermediación, vinculación con el entorno macroeconómico, regulación bancaria, decisiones de la banca comercial en contextos de información perfecta e imperfecta, conveniencia de las fusiones y adquisiciones, quiebras y riesgo sistémico.

Entre las investigaciones teóricas y empíricas que han examinado la evolución de las actividades de la banca comercial respecto a su rentabilidad y eficiencia operativa, la mayoría ha estudiado los casos de la banca estadounidense y europea, y coinciden en señalar que a mayor concentración y tamaño de las instituciones financieras es mayor la rentabilidad. Entre éstas se encuentran: Baltensperger (1972), Gilbert (1984), Berger y Hannan (1989), Liang (1989), Hannan (1991), Petersen y Rajan (1995), Boyd y De Nicolo (1995), Koskela (2000), Pillof y Rhoades (2002), Williams (2003), Shaffer (2004) y Degryse y Ongena (2007).

Por el contrario, otros trabajos afirman que los bancos pequeños pueden ser mayores en rentabilidad que los bancos grandes porque muestran menores costos y mayor eficiencia de operación. En esta línea se orientan las investigaciones de Allen y Rai (1996), Mester et al. (1998), Akhibe y McNulty (2003), Luo (2003) y Hannan y Prager (2009). Otros estudios han explorado la relación entre la rentabilidad de la banca y la regulación, por ejemplo, Zarruk y Madura (1992), Evanoff y Segal (1997), Ahmad, Ariff y Skully (2008) y Koutsomanoli et al. (2009). Se ha tratado también la pertinencia de considerar conceptos de eficiencia vinculados a las prácticas cotidianas de las empresas y sus efectos en la rentabilidad, como en Berger et al. (2000), Berger, Leusner y Mingo (1997) y Berger y Mester (1997).

Las condiciones de rentabilidad, operación, eficiencia y la misma evolución de la banca comercial en México y en Latinoamérica han estado permeadas por los acontecimientos históricos y factores institucionales, que delinearon su estado actual en clara distinción con los casos norteamericano y europeo. Entre las investigaciones que han resaltado estos elementos se encuentran: Boncheva (2000), Correa (2002), Girón (2002), Correa y Maya (2002), Girón y Correa (2004), Núñez (2005), Murillo (2002), Ávalos y Hernández (2006) y Ballescá (2007).

\section{Estructura y concentración de mercado de la banca comercial en México}

La historia reciente de la banca comercial se inicia con el escenario de crisis que experimentó la economía mexicana a inicios de la década de 1980, cuando concurrieron varios sucesos como el excesivo déficit fiscal y el endeudamiento público resultante 
de la continua solicitud de créditos a organismos financieros internacionales ${ }^{1}$, la caída de los precios internacionales del petróleo, la amplia salida de capitales extranjeros y la devaluación de la moneda nacional; simultáneamente, se decretó la nacionalización de la banca el $1^{\circ}$ de diciembre de 1982. Luego de este hecho, en agosto de 1983 el gobierno mexicano inició un proceso de reestructuración a través de la fusión de distintas instituciones y la recisión de otras; esto condujo al cambio sustancial en la estructura de la banca: antes de la nacionalización había 60 instituciones; en 1985 sólo eran 29; entre 1983 y 1990 siguió promoviéndose la reducción del número de instituciones: en 1986 sólo había 20, y en 1988 eran 18². La banca nacionalizada de este periodo se clasificaba, de acuerdo con la cobertura de sus servicios, en nacional, multirregional y regional.

A pesar de las dificultades de recuperación de la economía mexicana, la banca evolucionó favorablemente: por ejemplo, entre 1982 y 1988, la captación de recursos aumentó en promedio $4.3 \%$ anual en términos reales; el ahorro financiero que antes representaba alrededor de $32 \%$ del PIB, aumentó al $40 \%$, y la cartera de crédito como proporción del PIB se incrementó de $17 \%$ al 25 por ciento 3 .

Como consecuencia de la crisis provocada por el endeudamiento externo, durante los primeros años de la década de 1980, la política del gobierno de Miguel de la Madrid Hurtado (1983-1988) se propuso reducir el gasto público programable mediante las siguientes acciones: 1) privatización de organismos y empresas públicas no prioritarias (en el periodo, el Estado mantuvo siempre la propiedad de la banca); 2) cancelación de proyectos de inversión no prioritarios; y 3) reducción del número de dependencias oficiales. Así, mientras en 1982 existían 690 unidades administrativas entre direcciones y coordinaciones generales, en 1985 esta cifra disminuyó a 187 dependencias; esta reducción administrativa afectó principalmente al personal ocupado: se cancelaron puestos oficiales, plazas de confianza y se promovió el retiro voluntario.

El proceso de modificaciones legales y reformas para el sector financiero ocurrió principalmente a partir de 1990, en ese año se modificó la Constitución Política de los

1 Durante la década de 1970 y principios de los ochenta, el gobierno mexicano afirmaba que la mejor fuente de recursos para financiar la inversión y el desarrollo de las actividades productivas esenciales se hallaba en la contratación de créditos con organismos internacionales. De este modo se recibieron continuos préstamos del Banco Mundial, el Fondo Monetario Internacional, el Banco Interamericano de Desarrollo y el Banco Internacional de Reconstrucción y Fomento; estos préstamos se dirigieron sobre todo a la inversión en infraestructura pública, programas de salud e impulso de las actividades agrícolas.

2 Datos de la Asociación de Bancos de México, http://www.abm.org.mx

3 Banco de México (2007: 20-21). 
Estados Unidos Mexicanos para terminar con la exclusividad estatal de prestar los servicios bancarios, se publicaron la Ley de Instituciones de Crédito y la Ley para Regular las Agrupaciones Financieras ${ }^{4}$, también se dieron a conocer los lineamientos para la desincorporación de la banca múltiple, y con ello la posibilidad de que el servicio de banca y crédito pudiera ser otorgado por el sector privado; se determinaron los límites máximos de financiamiento que los bancos pueden ofrecer; se emitieron nuevas reglas para la operación de tarjetas de crédito; se reformó el régimen de inversión de las cuentas de ahorro y se estableció que la participación extranjera en la banca no podría exceder del $30 \%$ del capital 5 .

Varios principios y objetivos se siguieron en el proceso de desincorporación, entre ellos: $a$ ) contribuir a la creación de un sistema financiero competitivo y eficiente; $b$ ) promover la descentralización de las operaciones en la banca; $c$ ) favorecer el desarrollo regional de las instituciones; $d$ ) obtener precios justos por la venta, y d) asegurar el control de los bancos por parte de mexicanos pero incluyendo la participación minoritaria de los inversionistas extranjeros (Aspe, 1993). Entre junio de 1991 y julio de 1992 se privatizaron todos los bancos estatales; la explicación para la celeridad con que se llevó a cabo este proceso fue que así se evitaba otorgar ventajas competitivas (por el posicionamiento en el mercado) a los primeros bancos.

A inicios de los noventa, la situación de la banca parecía prometedora; entonces se establecieron medidas dirigidas a incrementar la competencia a través de un proceso de liberalización financiera; así se autorizó a diversas instituciones para que realizaran operaciones de intermediación no bancaria (entre éstas se encontraban casas de cambio, afianzadoras, aseguradoras y compañías de arrendamiento y factoraje), también se permitió que la banca determinara libremente las tasas de interés y los plazos en sus operaciones activas y pasivas, y se le autorizó para invertir discrecionalmente los recursos provenientes de captación. El resultado inmediato fue contrario a lo esperado: la agresiva liberalización ocasionó la expansión desmedida del crédito, y el sector hubo de enfrentar los problemas causados por el sobreendeudamiento y la incapacidad de pago de las familias y empresas.

4 La Ley General de Organizaciones y Actividades Auxiliares de Crédito, publicada el 14 de enero de 1985, tuvo modificaciones hasta 1994, para regular la participación de la banca extranjera a través de las filiales que mantengan en México.

5 Banco de México (1991: 66 ss.).

6 Se ha estimado que entre 1988 y 1994 el financiamiento directo al sector privado creció 24\% anual, mientras que el otorgado a través de tarjetas de crédito creció $31 \%$ anual. Ampudia (2003: 146 ss.). 
Al problema del crédito se añadieron otros factores negativos de la economía, principalmente el déficit de la cuenta corriente, las fluctuaciones (devaluaciones) del tipo de cambio y los constantes ajustes en el régimen cambiario, creciente inflación y el crecimiento excesivo de las tasas de interés?

Respecto a las modificaciones legales para el sector financiero en el periodo previo a la crisis, es importante destacar los cambios referentes al encaje legal y la autonomía del Banco de México. El encaje legal fue un instrumento mediante el que se obligaba a los bancos comerciales a mantener cierto porcentaje de sus pasivos en el Banco Central. Su finalidad principal era proporcionar recursos al gobierno federal y canalizar recursos hacia los sectores prioritarios de la economía que difícilmente podían acceder a créditos del sistema financiero; en menor medida se utilizó como un instrumento para el control de la cantidad de dinero en circulación ${ }^{8}$.

El encaje legal estuvo en vigencia desde 1925, año en que se fundó el Banco de México, y hasta 1989, cuando se estableció un coeficiente de liquidez del 30\%, porcentaje de la captación que los bancos comerciales debían mantener como depósitos en el Banco Central o en valores gubernamentales. En marzo de 1995, el coeficiente de liquidez se eliminó cuando se adoptó una política de objetivos de inflación y se sustituyó por el instrumento conocido como la variación de saldos acumulados; desde abril de 2003 se utiliza el saldo objetivo diario y a partir del 21 de enero de 2008 se sustituye por el objetivo operacional de tasas de interés de fondeo interbancario.

El encaje legal estuvo asociado a los controles selectivos del crédito, éstos tuvieron una dudosa efectividad en el impulso de algún área de la actividad económica porque parecían responder a cuestiones coyunturales, más que a proyectos de largo plazo.

7 Entre diciembre de 1994 y marzo de 1995, las tasas de interés cambiaron de 20\% anual a 110\% anual. Ampudia (2003: 147).

8 Desde su creación, la política del encaje legal experimentó continuas modificaciones, se aplicaron tasas diferenciadas según los tipos de pasivos o la localización geográfica, se impusieron tasas marginales sobre los excedentes de los pasivos que se hubieran mantenido respecto a alguna fecha, y se modificaron según las necesidades de recursos del sector público. Como ejemplos de estas modificaciones destacan: en 1972, el coeficiente de encaje se reduce al 40\% para los nuevos pasivos de las sociedades financieras; en 1975, el coeficiente de encaje se incrementa al $50 \%$ y se establece un encaje marginal del $77 \%$ en la zona metropolitana y del $54 \%$ en el resto del país para los pasivos excedentes respecto a los que se tenían el 27 de septiembre de 1974; en 1977 se incrementa al 77\% el encaje sobre pasivos en dólares y se establece la tasa única del $37.5 \%$ sobre pasivos en moneda nacional para las instituciones de banca múltiple; en 1979, la tasa general de encaje se incrementa a 40.9\%; en agosto de 1988 se impone un nuevo régimen de encaje marginal del $51 \%$ sobre los excedentes de pasivos mantenidos hasta julio del mismo año (10\% en depósitos en el Banco de México, $31 \%$ en créditos al gobierno federal y $10 \%$ a la banca de desarrollo). 
En agosto de 1993, se modificó el artículo 28 constitucional de la República Mexicana para otorgar autonomía al Banco de México; y en diciembre del mismo año se aprobó la Ley del Banco de México. En la nueva reglamentación se establece que la institución puede otorgar créditos al gobierno federal y a organismos de crédito; para el gobierno, los créditos tienen un límite de 1.5\% del total del Presupuesto de Egresos de la Federación para el año que se trate, no obstante, en el caso de exceder ese límite, el Banco Central puede emitir valores públicos con cargo al gobierno federal'

La crisis económica y el colapso del sistema bancario obligaron a que el Banco de México en 1994 absorbiera los pasivos del Fondo Bancario de Protección al Ahorro (Fobaproa) y del Fondo de Apoyo al Mercado de Valores (Fameval); estos pasivos fueron concentrados por el Instituto para la Protección del Ahorro Bancario (IPAB) en 1999. Cabe mencionar que el programa de rescate bancario incluyó la aprobación de la Ley de Protección al Ahorro Bancario el 19 de enero de 1999, que reglamenta las actividades del IPAB; en ese año, el organismo asumió la titularidad de las operaciones de financiamiento de siete bancos comerciales, se encargó de las operaciones de 10 instituciones bancarias intervenidas por la Comisión Nacional Bancaria y de Valores (CNBV) y de seis entidades financieras intervenidas por el Fameval ${ }^{10}$.

En conjunto, para el año 2000 el IPAB reconoció mantener una deuda con el Banco de México de 23987953287.05 Unidades de Inversión (Udis). En la actualidad, gracias a sus programas de financiamiento que incluyen recursos del presupuesto público, cuotas aportadas por los bancos comerciales y por la banca de desarrollo, además de la emisión de valores públicos, la deuda asumida por el IPAB, producto del rescate bancario (y que por reglamentación no se considera

9 La reglamentación original de 1993 establecía que el Banco de México también podía otorgar crédito a los fondos bancarios de Protección al Ahorro y de Apoyo al Mercado de Valores; en la modificación aprobada el 19 de enero de 1999, se establece como facultad del Banco de México otorgar crédito al gobierno federal, a instituciones de crédito y al organismo descentralizado denominado Instituto para la Protección del Ahorro Bancario.

10 Los bancos comerciales apoyados fueron: Banco Bilbao-Vizcaya México S.A., Banco Mexicano S.A., Banco del Centro S.A., Banpaís S.A., Confía S.A., Grupo Financiero Serfín S.A. y Banca Serfín S.A., Grupo Financiero Inverlat S.A de C.V. y Banco Inverlat S.A. Las instituciones intervenidas: Banca Cremi S.A., Banco Capital S.A., Banco de Oriente S.A., Banco Interestatal S.A., Banco Promotor del Norte S.A., Banca Unión S.A., Banco Obrero S.A., Banco Anáhuac S.A., Banco Industrial S.A., Banco del Sureste S.A. Las entidades financieras intervenidas: Casa de Bolsa Arka S.A. de C.V., Bursamex S.A. de C.V., Estrategia Bursátil S.A. de C.V., Mexival Banpaís Casa de Bolsa S.A. de C.V., Valores Bursátiles de México S.A. de C.V., e Inmobiliaria Adela S.A. de C.V. 
deuda pública), es de 15192370410 Udis, el equivalente a 48615585310 pesos mexicanos ${ }^{11}$.

Como consecuencia de esta crisis y como se preveía con el Tratado de Libre Comercio (TLC), entre 1995 y 1998 se origina la apertura del sector a la propiedad extranjera; en ese periodo se generó mucha polémica, por ejemplo, se argumentaba que la participación extranjera sería benéfica porque habría mayor disponibilidad de fondos y movilidad del capital, y porque mejoraría la eficiencia ${ }^{12}$.

Al principio, la banca extranjera participó bajo condiciones muy restrictivas, se determinó que su participación individual tendría que ser menor o igual al $1.5 \%$ en el mercado, y globalmente el total de la banca extranjera podría ocupar menos del $8 \%$ del mercado. Con el TLC también se estableció que el gobierno mexicano podría congelar el capital extranjero si la participación de la banca superaba el 25\% del sistema; asimismo, se limitó al 30\% del capital la participación accionaria del capital extranjero en los bancos mexicanos ${ }^{13}$. A finales de 1993, Citibank era el único banco extranjero en México, sus activos representaban 0.5\% del total del sistema; en 1994 se incorporaron cuatro bancos más: GE Capital, Santander, JP Morgan y Chase Manhattan.

La expansión de la banca extranjera en México ha evolucionado en dos etapas: la primera, con la entrada en vigor del TLC, cuando la legislación amplió la participación de cada banco individual extranjero de $1.5 \%$ a $6 \%$; la participación global se extendió de $8 \%$ a $25 \%$, y la participación accionaria de $30 \%$ a $49 \%$. La segunda etapa ocurrió en el año 2000, cuando se eliminaron totalmente las restricciones al capital extranjero: en ese año BBV adquirió Bancomer y al año siguiente Citibank controló Banamex, y HSBC, Bital. Se estima que a finales de 2003 la participación extranjera ya ascendía a 82.3 por ciento $^{14}$.

Para evaluar el impacto de la entrada del capital extranjero en la banca, es útil examinar el grado de concentración de ésta. Al estimar el Índice Herfindahl-Hirschman $(H H I)^{15}$ considerando como base la cantidad de activos en proporción al total del

11 Los bonos que emite el IPAB son los Bonos para la Protección al Ahorro Bancario con tasa de interés revisable cada 28 días (BPA's) y cada 91 días (BPAT's).

12 La explicación detallada de estos argumentos se encuentra en Correa y Maya (2002).

13 Banco de México (2007: 32 ss.).

14 El Banco de México observa que la proporción del capital extranjero estaba distribuida de la siguiente forma en el año 2003: 37.6\% de España (BBV-Bancomer y Santander-Serfín); 27.6\% de los Estados Unidos (Banamex-Citibank, Bank of America, y otros); 10.1\% de Reino Unido (HSBC-Bital, ING Bank); 10.1\% de Canadá (Scotiabank-Inverlat), y alrededor del 8\% de otros países, entre ellos Alemania (Dresner Bank), y Japón (Bank of Tokio, y Fuji-Bank). Banco de México (2007: 35).

15 En el Anexo 1 se hace una explicación detallada del procedimiento de cálculo del Índice Herfindahl-Hirschman. 
sistema, se observan claramente los efectos de la crisis económica de mediados de los noventa y de la participación del capital extranjero con el TLC. Entre 1991 y 1992, el índice se ubicó entre 0.15 y 0.13, y de 1994 a 1999, entre 0.11 y 0.09, es decir que en esos últimos años la concentración del mercado fue menor, sobre todo por la acelerada expansión del capital extranjero. El lapso 2000-2009 muestra concentración moderada: entre 0.128854 y 0.162228 , y concentración promedio de 0.147173 . Este incremento en la concentración, a pesar de que existen actualmente 43 instituciones reconocidas de banca múltiple, se explica por la consolidación de la banca extranjera en unas cuantas instituciones (las de mayor tamaño), mientras que una participación inferior se encuentra en los bancos muy pequeños.

Gráfica 1

Índice de concentración de activos de la banca comercial en México, 1991-2000

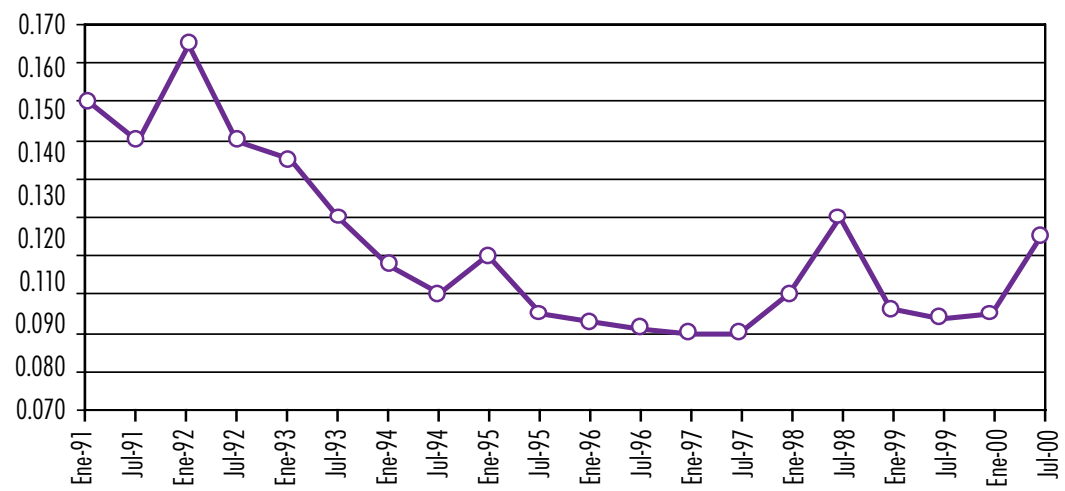

Fuente: Elaboración propia con base en información del Banco de México y de Murillo, 2002.

Gráfica 2

Índice de concentración de activos de la banca comercial en México, 2001-2009

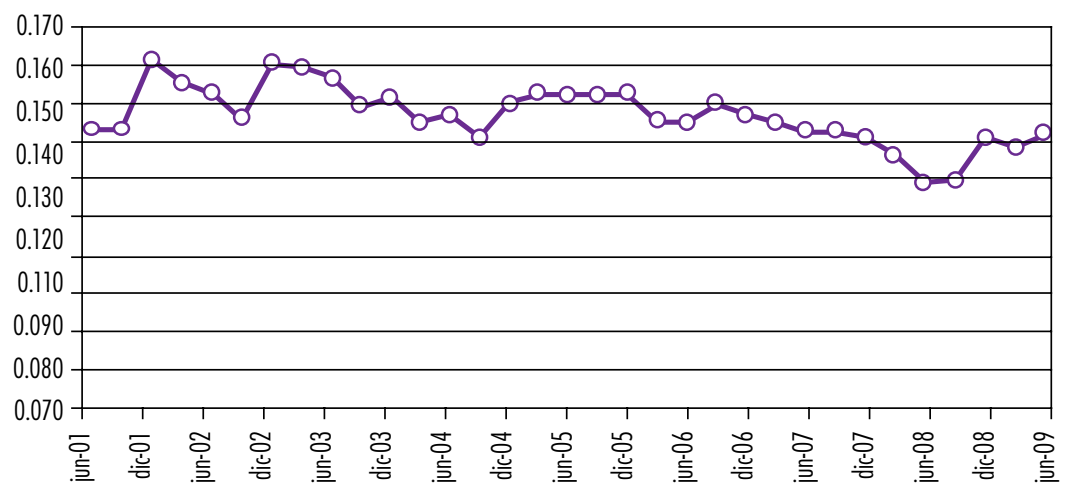

Fuente: Elaboración propia con base en información de la Comisión Nacional Bancaria y de Valores. 
En los años recientes se ha observado la proliferación de pequeños bancos cuyos servicios se dirigen principalmente a los pequeños ahorradores y solicitantes de créditos; en gran medida, estas nuevas instituciones vinculan el otorgamiento de esos servicios con su actividad primordial de comercialización de bienes en tiendas departamentales y de autoservicio.

Cuadro 1

Clasificación de la banca comercial en México y participación en el mercado

\begin{tabular}{|c|c|c|c|c|c|}
\hline Fecha & Tamaño & Bancos & Sucursales & $\%$ Activos & $\%$ Pasivos \\
\hline \multirow[t]{4}{*}{ Junio 2001} & Grandes & 2 & 3522 & 45.38 & 44.65 \\
\hline & Medianos & 5 & 2967 & 34.41 & 35.87 \\
\hline & Pequeños & 3 & 368 & 9.61 & 8.79 \\
\hline & Muy pequeños & 24 & 136 & 10.60 & 10.69 \\
\hline \multirow[t]{4}{*}{ Junio 2002} & Grandes & 2 & 3112 & 46.98 & 45.81 \\
\hline & Medianos & 4 & 3385 & 33.75 & 35.11 \\
\hline & Pequeños & 4 & 382 & 10.44 & 9.49 \\
\hline & Muy pequeños & 21 & 157 & 8.83 & 9.59 \\
\hline \multirow[t]{4}{*}{ Junio 2003} & Grandes & 2 & 3052 & 49.80 & 49.30 \\
\hline & Medianos & 4 & 3299 & 32.80 & 34.40 \\
\hline & Pequeños & 3 & 407 & 10.30 & 9.80 \\
\hline & Muy pequeños & 23 & 1007 & 7.00 & 6.50 \\
\hline \multirow[t]{4}{*}{ Junio 2004} & Grandes & 2 & 2999 & 47.66 & 47.23 \\
\hline & Medianos & 4 & 3265 & 33.51 & 34.97 \\
\hline & Pequeños & 5 & 424 & 12.10 & 11.58 \\
\hline & Muy pequeños & 21 & 1045 & 6.73 & 6.22 \\
\hline \multirow[t]{4}{*}{ Junio 2005} & Grandes & 3 & 3934 & 60.92 & 60.60 \\
\hline & Medianos & 3 & 2690 & 24.53 & 25.83 \\
\hline & Pequeños & 5 & 1064 & 9.39 & 8.93 \\
\hline & Muy pequeños & 18 & 163 & 5.16 & 4.64 \\
\hline \multirow[t]{4}{*}{ Junio 2006} & Grandes & 3 & 4077 & 59.91 & 59.91 \\
\hline & Medianos & 3 & 2740 & 24.44 & 25.31 \\
\hline & Pequeños & 5 & 1165 & 10.02 & 9.64 \\
\hline & Muy pequeños & 19 & 192 & 5.64 & 5.14 \\
\hline \multirow[t]{4}{*}{ Junio 2007} & Grandes & 2 & 3305 & 43.80 & 43.50 \\
\hline & Medianos & 4 & 3774 & 39.10 & 39.80 \\
\hline & Pequeños & 5 & 1279 & 10.30 & 10.10 \\
\hline & Muy pequeños & 28 & 359 & 6.80 & 6.60 \\
\hline \multirow[t]{4}{*}{ Junio 2008} & Grandes & 2 & 3485 & 39.90 & 39.60 \\
\hline & Medianos & 4 & 3465 & 39.80 & 40.10 \\
\hline & Pequeños & 7 & 1953 & 14.00 & 14.40 \\
\hline & Muy pequeños & 29 & 1077 & 6.30 & 6.00 \\
\hline \multirow[t]{4}{*}{ Junio 2009} & Grandes & 2 & 3428 & 44.48 & 44.53 \\
\hline & Medianos & 3 & 3320 & 33.38 & 33.90 \\
\hline & Pequeños & 8 & 2314 & 15.98 & 15.69 \\
\hline & Muy pequeños & 30 & 1425 & 6.15 & 5.86 \\
\hline
\end{tabular}

Fuente: Elaboración propia. 


\section{Rentabilidad y eficiencia operativa de la banca comercial}

La investigación acerca de la rentabilidad y la eficiencia operativa se realizó a partir del análisis de los estados financieros de cada banco comercial con actividades en México entre los años 2002 y 2009; para ello se utilizaron los datos reportados trimestralmente por la Comisión Nacional Bancaria y de Valores (CNBV).

Otros estudios que han evaluado rentabilidad y eficiencia sólo han considerado la situación general de la banca, sin distinguir las particularidades por tipo de banco. Esto se debe principalmente a la carencia de información para evaluar el periodo previo al año 2000; con anterioridad a esa fecha sólo se dispone de datos financieros para el total del sistema bancario, y no se encuentra información sistematizada de los estados financieros de cada banco ${ }^{16}$.

En estudios generales sobre el sistema bancario, la presunción es que el sector es altamente rentable, principalmente por la considerable diferencia entre las tasas de interés activa y pasiva de sus operaciones; sin embargo, se considera ineficiente en relación con el escaso financiamiento que proporciona a la actividad productiva ${ }^{17}$.

En esta investigación se calcularon indicadores estándar de rentabilidad y eficiencia operativa de cada banco, a partir del balance general y del estado de resultados, con la finalidad de evaluar si el comportamiento de la banca ha sido homogéneo e independiente del grado de concentración del sistema y del tamaño de cada institución, a la vez que así se aprovecha la riqueza de información disponible en los años recientes.

Hemos considerado conveniente clasificar las instituciones definiendo la variable $x$ como la participación en volumen de activos respecto al total de la banca, en la siguiente forma: $a$ ) bancos grandes, $x>15 \%$ (poseen más de $15 \%$ del total de activos); b) bancos medianos, $15 \% \leq x \leq 5 \%$ (poseen entre $5 \%$ y $15 \%$ del total de los activos); c) bancos pequeños, $1 \% \leq x<5 \%$ (poseen $1 \%$ o más del total de los activos, pero menos de 5\%); $d$ ) bancos muy pequeños, $x<1 \%$ (poseen menos de $1 \%$ de activos). En el cuadro 1 se muestran los resultados de esta clasificación para la banca con operaciones en México entre junio de 2001 y junio de $2009^{18}$.

16 En México hace apenas unos años que se obliga a la banca comercial a reportar mensualmente sus estados financieros completos a la Comisión Nacional Bancaria y de Valores, institución que se compromete a su difusión; además, este organismo se constituyó recientemente, el 28 de abril de 1995.

17 Véase por ejemplo, Castillo y Martínez (2007).

18 Como ejemplo de la magnitud de los activos de la banca comercial en México, se muestran cifras de junio de 2009. En esta fecha, el total de activos era de \$4 760858.60 millones de pesos; así, los bancos grandes poseen activos de más de $\$ 714000.00$ millones, los bancos medianos 
Para cada banco y cada grupo de bancos se calcularon los siguientes indicadores ${ }^{19}$ : 1) $R O A$, rendimiento sobre activos.

$$
R O A=\frac{\text { Ingreso neto }}{\text { Total de activos }}
$$

2) $R O E$, rendimiento sobre capital.

$$
R O E=\frac{\text { Ingreso neto }}{\text { Capital contable total }}
$$

3) MNI, margen neto por intereses.

$$
M N I=\frac{\text { Ingresos por intereses }- \text { Gastos por intereses }}{\text { Total de activos }}
$$

4) $M N O$, margen neto de operación.

$$
M N O=\frac{\text { Ingresos por intereses }- \text { Gastos por intereses }}{\text { Total de activos }}
$$

5) $M U$, margen de utilidad.

$$
M U=\frac{\text { Ingreso neto }}{\text { Ingresos totales por operaciones }}
$$

6) $R A$, rotación de activos.

$$
R A=\frac{\text { Ingresos totales por operaciones }}{\text { Total de activos }}
$$

7) $M C$, multiplicador del capital.

$$
M C=\frac{\text { Total de activos }}{\text { Capital contable total }}
$$

8) $E O$, eficiencia operativa.

$$
E O=\frac{\text { Gastos por operaciones }}{\text { Total de activos }}
$$

entre $\$ 238000.00$ y $\$ 714000.00$ millones, los bancos pequeños entre $\$ 47000.00$ y 238000.00 , y los bancos muy pequeños poseen menos de $\$ 47000.00$ millones de pesos.

19 En Ross y Hudgins (2008) se muestran algunos estudios empíricos que han evaluado la rentabilidad y la eficiencia de la banca estadounidense a partir del análisis sistemático de los estados financieros. Para el caso de México no se conocen estudios similares. 
Cuadro 2

Comparativo de indicadores de rentabilidad y eficiencia operativa de acuerdo con el tamaño de los bancos comerciales

\begin{tabular}{|c|c|c|c|c|c|}
\hline & Valores & Grandes & Medianos & Pequeños & Muy pequeños \\
\hline \multirow[t]{3}{*}{$R O A$} & máximo & 0.03927 & 0.02754 & 0.04234 & 0.06042 \\
\hline & mínimo & -0.00026 & -0.04205 & 0.00010 & -0.00609 \\
\hline & promedio & 0.01210 & 0.00935 & 0.00969 & 0.00778 \\
\hline \multirow[t]{3}{*}{ ROE } & máximo & 0.25600 & 0.32630 & 0.29732 & 0.37033 \\
\hline & mínimo & -0.00210 & -0.75109 & 0.00038 & -0.05477 \\
\hline & promedio & 0.09668 & 0.10266 & 0.07597 & 0.05491 \\
\hline \multirow[t]{3}{*}{ MNI } & máximo & 0.07478 & 0.06936 & 0.06157 & 0.21163 \\
\hline & mínimo & 0.01010 & 0.00594 & -0.08446 & 0.00119 \\
\hline & promedio & 0.03568 & 0.03202 & 0.02406 & 0.03300 \\
\hline \multirow[t]{3}{*}{ MNO } & máximo & 0.06176 & 0.03629 & 0.03908 & 0.04045 \\
\hline & mínimo & 0.00051 & -0.02982 & -0.00727 & -0.02950 \\
\hline & promedio & 0.01810 & 0.01051 & 0.00756 & -0.00373 \\
\hline \multirow[t]{3}{*}{ MU } & máximo & 0.44172 & 0.60755 & 0.50698 & 0.99161 \\
\hline & mínimo & -0.00390 & -0.92967 & 0.05572 & -0.24230 \\
\hline & promedio & 0.27503 & 0.25440 & 0.57731 & 0.35736 \\
\hline \multirow[t]{3}{*}{$R A$} & máximo & 0.09791 & 0.08834 & 0.07071 & 0.25300 \\
\hline & mínimo & 0.01161 & 0.00860 & 0.00015 & 0.00441 \\
\hline & promedio & 0.04400 & 0.03855 & 0.02385 & 0.03609 \\
\hline \multirow[t]{3}{*}{$M C$} & máximo & 14.43050 & 24.58974 & 20.17448 & 25.01276 \\
\hline & mínimo & 4.88371 & 5.84889 & 2.13037 & 3.42820 \\
\hline & promedio & 8.29403 & 13.13965 & 8.97799 & 8.80336 \\
\hline \multirow[t]{3}{*}{ EO } & máximo & 0.05465 & 0.07505 & 0.05559 & 0.17356 \\
\hline & mínimo & 0.00454 & 0.00531 & 0.00090 & 0.00394 \\
\hline & promedio & 0.02591 & 0.02805 & 0.01628 & 0.02651 \\
\hline
\end{tabular}

Fuente: Elaboración propia.

En el cuadro 2 se contrastan los resultados de estos indicadores por grupo de bancos. Respecto a la razón de rendimientos sobre activos $R O A$, que evalúa la capacidad de la administración para generar rendimientos a partir de sus recursos, se encontró que es mayor en el caso de los bancos grandes y de los pequeños; el indicador está relacionado de manera positiva con la eficiencia operativa en los bancos de menor tamaño, lo que indica que en estos casos, a pesar de elevados gastos de operación, el ROA puede incrementarse por otras causas, por ejemplo, debido a la rotación de activos.

Es importante destacar que en algunos casos se obtuvieron valores negativos del $R O A$ (y, por lo tanto, del $R O E$ ) porque los bancos reportaron utilidades netas negativas, o bien, se encontraron signos negativos para algunas fechas en ciertos componentes del ROA. Recordemos que el ROA puede expresarse alternativamente como:

$R O A=M N I+M N O-$ Transacciones especiales que afectan el ingreso neto 
Durante todo el periodo de observación sólo uno de los bancos grandes reportó utilidades negativas, y ello ocurrió en una sola fecha; en cambio, en los bancos muy pequeños se observó que con frecuencia el margen neto de operación resulta negativo.

Salvo en algunos casos excepcionales de bancos muy pequeños que han presentado un rendimiento sobre capital ROE, de más de $35 \%$, en general este indicador ha sido mayor en los bancos grandes y medianos, lo que se explica por el uso intensivo del apalancamiento financiero con la finalidad de reportar dividendos positivos a los accionistas; este hecho se debe a la descomposición del $R O E$ en la siguiente forma:

$$
R O E=M U \times R A \times M C
$$

Resulta interesante observar también la evolución de las razones de rentabilidad

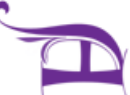
$R O A$ y $R O E$, y su contraste según el tamaño de las instituciones financieras; puede afirmarse que si bien la rentabilidad de la banca ha permanecido estancada desde 2008, es considerable la superioridad de los bancos grandes y medianos en la generación de beneficios. Esto se muestra en las gráficas 3 y 4.

Gráfica 3

Evolución del Rendimiento sobre activos (ROA) de la banca comercial en México

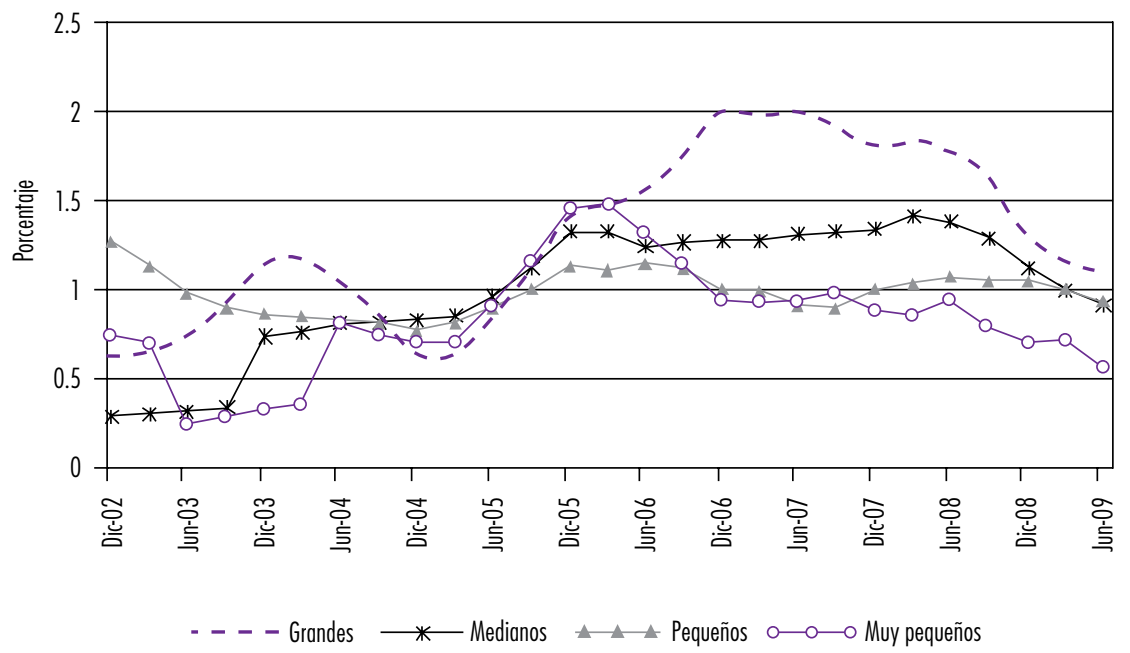

Nota: En la gráfica se muestran las cifras desestacionalizadas y promedio de los rendimientos calculados en cada grupo de bancos.

Fuente: Elaboración propia. 
Gráfica 4

Evolución del Rendimiento sobre capital (ROE) de la banca comercial en México

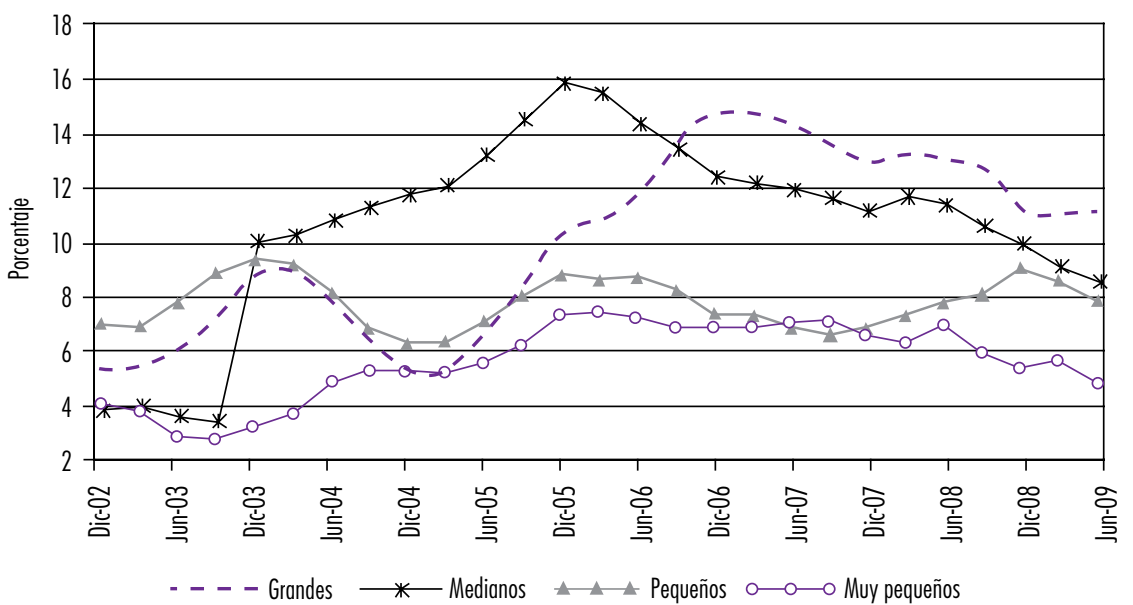

Nota: En la gráfica se muestran las cifras desestacionalizadas y promedio de los rendimientos calculados en cada grupo de bancos.

Fuente: Elaboración propia.

En la descomposición del ROA, es muy útil evaluar la procedencia de las utilidades netas. En el caso de los bancos grandes, la mayoría de las utilidades proviene de las ventajas de escala que les otorga su infraestructura, esto se aprecia claramente en el margen neto de operación $M N O$ (la diferencia entre los ingresos y los gastos por operaciones, ponderada entre el total de activos) que ha sido tradicionalmente mayor en estos bancos. En la gráfica 5 se muestra que los bancos grandes son también más ventajosos en generar rendimientos a partir del margen neto de intereses MNI (la diferencia entre los ingresos y los gastos resultantes de intereses, ponderada entre el total de activos); se observa también que hasta 2005 , los bancos muy pequeños tenían amplia ventaja en este indicador, y además, desde 2008, se percibe una tendencia decreciente en todos los bancos. Un margen neto de intereses elevado puede indicar prácticas exitosas de administración de riesgos, caracterizadas por la selección óptima de títulos en activos y pasivos, aunque también puede sugerir políticas de otorgamiento de créditos en condiciones desfavorables para los prestatarios. En el caso de los bancos medianos y grandes que operan en México, el margen neto de operación es mayor porque estas instituciones cuentan con un posicionamiento en el mercado y también con la capacidad e infraestructura para obtener ventajas por la escala de operaciones que ejecutan; la amplitud del margen neto de intereses responde al poder de mercado de los bancos que les permite fijar considerables tasas activas, la selección óptima de 
sus activos se ha concentrado en los créditos a las actividades comerciales y créditos personales dirigidos a la población de ingresos medios ${ }^{20}$.

\section{Gráfica 5}

Evolución del Margen neto de intereses (MNI) de la banca comercial en México

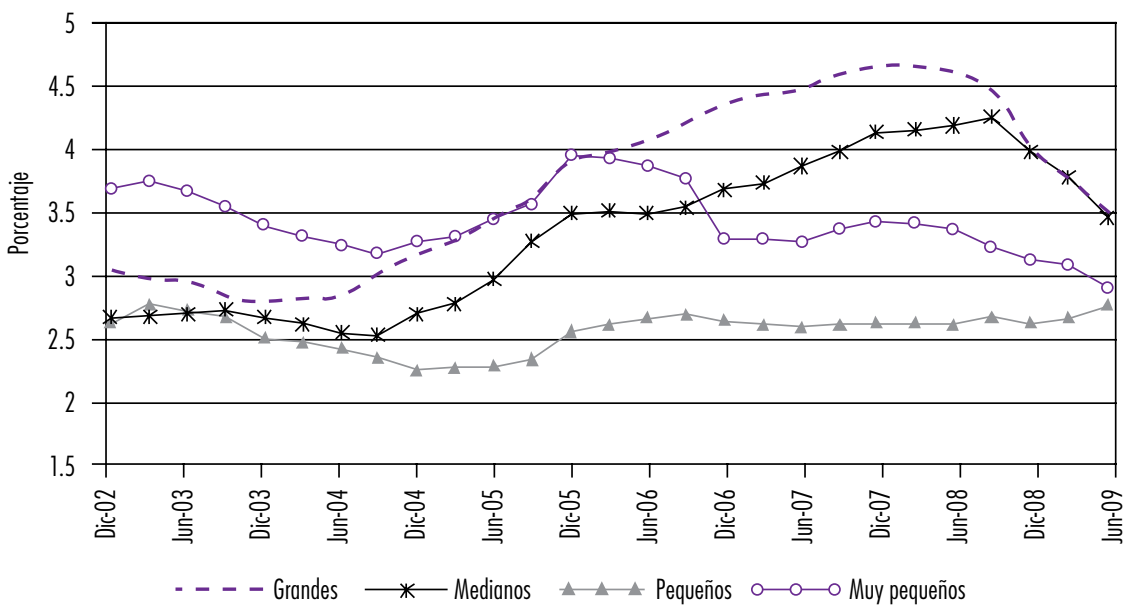

Nota: En la gráfica se muestran las cifras desestacionalizadas y promedio de los rendimientos calculados en cada grupo de bancos.

Fuente: Elaboración propia

Dos indicadores estrechamente vinculados con el control de las actividades son la rotación de activos $R A$ y la eficiencia operativa $E O$, las instituciones más eficientes son las que exhiben elevado $R A$ y reducido $E O$. En coincidencia con las observaciones anteriores, los bancos grandes y los pequeños muestran mayor eficiencia (véase cuadro 2).

El multiplicador del capital $M C$ revela la preferencia del banco por el financiamiento mediante capital propio o endeudamiento; su disminución está frecuentemente vinculada a la regulación del sector financiero por la autoridad monetaria a través de la imposición de requerimientos mínimos de capital. En el caso de México, se observa la tendencia al endeudamiento de las instituciones desde finales de 2007. La mayor presencia de los bancos muy pequeños en los años recientes está fuertemente relacionada con su excesivo apalancamiento; estos bancos se han expandido sobre todo por su introducción conjunta con tiendas comerciales y de autoservicio. La mayoría ofrece atractivos rendimientos a los depósitos, y otorga gran número de créditos con elevadas tasas de interés; estas operaciones se dirigen principalmente a

20 La amplia magnitud de los ingresos por intereses para el total de la banca se muestra en la gráfica A1 del Anexo 2. 
la población de menores ingresos. La demanda de nuevos créditos por parte de este mercado motiva a los bancos a recurrir a financiamiento externo, o con filiales, de ahí su elevado apalancamiento ${ }^{21}$. Cuando el apalancamiento es elevado, la rentabilidad sobre el capital tiende a incrementarse, esto se observa en la ecuación (10), así, los bancos muy pequeños se aseguran de atraer nuevos recursos con magnitudes considerables de apalancamiento, no sólo por el financiamiento directo que pueden recibir, sino también porque la $R O E$ es elevada y esto atrae a nuevos inversores, quienes suponen que estos resultados se deben a la eficiencia del banco ${ }^{22}$.

La vinculación entre los indicadores estimados se analizó también a través

Gráfica 6

Evolución del Multiplicador del capital $(M C)$ de la banca comercial en México

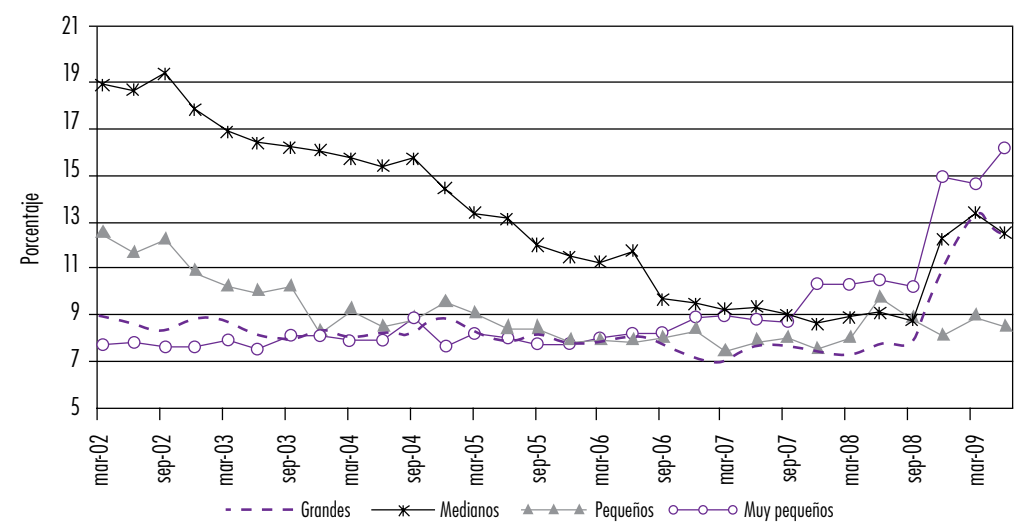

Nota: En la gráfica se muestran las cifras promedio calculadas en cada grupo de bancos. Fuente: Elaboración propia.

21 Los efectos de la crisis económica de 2008 se perciben de modo notorio en el sector con el incremento del apalancamiento; la necesidad de atraer recursos por parte de la banca conduce a que éstas opten por financiamientos para sí mismas que les permitan reinvertir tales recursos y mejorar la rentabilidad sobre capital ROE. Esta situación se observa también en otras áreas no bancarias; es conocida, por ejemplo, la alta volatilidad en los precios de las acciones de algunas firmas como Vitro S.A.B. de C.V. y Controladora Comercial Mexicana S.A.B. de C.V., en ambos casos, el multiplicador de capital se incrementó en más de tres veces entre 2008 y 2009. Otro efecto de la reciente crisis en el sector bancario se revela en la cautela hacia la canalización de capital; con excepción de los bancos de menor tamaño, las instituciones han dirigido sus capitales a los títulos respaldados por los gobiernos, al respecto puede consultarse información en el Banco Internacional de Pagos, http://www.bis.org

22 Hay distintas interpretaciones para el concepto de eficiencia en la actividad de la banca. Comúnmente se vincula al entorno macroeconómico para subrayar que ha sido escaso si se comparan los costos financieros de sus operaciones con el financiamiento que proporciona a la actividad productiva, también se cuestiona el considerable esfuerzo que debe realizarse en materia de regulación y control. En otra acepción de eficiencia, sólo se observa la capacidad de la institución para generar considerables rendimientos, independientemente de su fuente. Otro concepto es el de eficiencia operativa, donde se evalúa el margen entre los ingresos por las operaciones (ingresos distintos a intereses) y los gastos. 
de regresiones con datos en panel. Se eligió como variable dependiente la razón de rentabilidad $R O E$, en función de las razones $M N I, M N O, M U, R A$ y $M C$; en la regresión se prescindió de la razón $E O$, dado que se encuentra incorporada en la magnitud del margen neto de operación; además, se usaron como variables independientes las razones calculadas, en lugar de las series directas provenientes de los estados financieros (activos, pasivos, utilidad neta, gastos e ingresos por operaciones, etc.), ya que el uso de éstas genera alta colinealidad. Se estimó una ecuación para cada tamaño de banco y en cada caso se eligieron sólo los bancos que han estado presentes en el mercado en todo el periodo considerado.

Cuadro 3

Resultados de la regresión en panel de datos, $R O E$ como variable dependiente

\begin{tabular}{|c|c|c|c|c|}
\hline \multicolumn{5}{|c|}{ A. Bancos grandes } \\
\hline \multicolumn{2}{|c|}{ Variable dependiente: ROE } & \multicolumn{3}{|c|}{ Muestra: $2002012009 Q 2$} \\
\hline \multicolumn{2}{|c|}{ Método: Mínimos cuadrados en panel } & \multicolumn{3}{|c|}{ Secciones - cruzadas: 2} \\
\hline \multicolumn{5}{|c|}{ Total de observaciones del panel (balanceado): 60} \\
\hline Variable & Coeficiente & Error estándar & Estadistico † & Probabilidad \\
\hline MNI & 1.870896 & 0.726865 & 2.573923 & 0.0128 \\
\hline MNO & 1.993473 & 0.698491 & 2.853970 & 0.0061 \\
\hline MU & 0.227276 & 0.047539 & 4.780871 & 0.0000 \\
\hline RA & -0.836728 & 0.668027 & -1.252537 & 0.2157 \\
\hline MC & -0.003263 & 0.001513 & -2.157660 & 0.0353 \\
\hline$R^{2}$ & 0.718659 & \multicolumn{2}{|c|}{ Media de variable dependiente } & 0.096673 \\
\hline$R^{2}$ ajustada & 0.698198 & \multicolumn{2}{|c|}{ Desviación estándar de var. dep. } & 0.066236 \\
\hline Error est. de regresión & 0.036388 & \multicolumn{2}{|l|}{ Criterio de Akaike } & -3.709518 \\
\hline Suma residuos cuad. & 0.072823 & \multicolumn{2}{|l|}{ Criterio de Schwarz } & -3.534990 \\
\hline Log verosimilitud & 116.2856 & \multicolumn{2}{|l|}{ Estadístico F } & 35.12313 \\
\hline Durbin-Watson & 1.183971 & \multicolumn{2}{|c|}{ Probabilidad (estadístico F) } & 0.000000 \\
\hline
\end{tabular}

\begin{tabular}{|c|c|c|c|c|}
\hline \multicolumn{5}{|c|}{ B. Bancos medianos } \\
\hline \multicolumn{2}{|c|}{ Variable dependiente: ROE } & \multicolumn{2}{|c|}{ Muestra: 2002Q1 2009Q2 } & \\
\hline \multicolumn{2}{|c|}{ Método: Mínimos cuadrados en panel } & \multicolumn{2}{|c|}{ Secciones - cruzadas: 3} & \\
\hline \multicolumn{5}{|c|}{ Total de observaciones del panel (balanceado): 90} \\
\hline Variable & Coeficiente & Error estándar & Estadístico † & Probabilidad \\
\hline MNI & -3.383050 & 1.031334 & -3.280266 & 0.0015 \\
\hline MNO & $4.05 E-05$ & 0.001105 & 0.036646 & 0.9709 \\
\hline MU & 6.412437 & 1.583146 & 4.050439 & 0.0001 \\
\hline$R A$ & 0.198756 & 0.042135 & 4.717160 & 0.0000 \\
\hline$M C$ & 2.581304 & 1.163206 & 2.219128 & 0.0291 \\
\hline$R^{2}$ & 0.741257 & \multicolumn{2}{|c|}{ Media de variable dependiente } & 0.102661 \\
\hline$R^{2}$ ajustada & 0.729081 & \multicolumn{2}{|c|}{ Desviación estándar de var. dep. } & 0.112992 \\
\hline Error est. de regresión & 0.058812 & \multicolumn{2}{|l|}{ Criterio de Akaike } & -2.774979 \\
\hline Suma residuos cuad. & 0.294005 & \multicolumn{2}{|c|}{ Criterio de Schwarz } & -2.636101 \\
\hline Log verosimilitud & 129.8741 & \multicolumn{2}{|l|}{ Estadístico F } & 60.87772 \\
\hline Durbin-Watson & 1.401814 & \multicolumn{2}{|c|}{ Probabilidad (estadistico F) } & 0.000000 \\
\hline
\end{tabular}




\begin{tabular}{|c|c|c|c|c|}
\hline \multicolumn{5}{|c|}{ C. Bancos pequeños } \\
\hline \multicolumn{2}{|c|}{ Variable dependiente: ROE } & \multicolumn{3}{|c|}{ Muestra: $2002012009 Q 2$} \\
\hline \multicolumn{2}{|c|}{ Método: Mínimos cuadrados en panel } & \multicolumn{3}{|c|}{ Secciones - cruzadas: 4} \\
\hline \multicolumn{5}{|c|}{ Total de observaciones del panel (balanceado): 120} \\
\hline Variable & Coeficiente & Error estándar & Estadístico $†$ & Probabilidad \\
\hline MNI & -0.777214 & 0.298983 & -2.599527 & 0.0106 \\
\hline MNO & 3.011682 & 0.486075 & 6.195925 & 0.0000 \\
\hline MU & 0.014891 & 0.005486 & 2.714200 & 0.0077 \\
\hline$R A$ & 2.369238 & 0.333586 & 7.102333 & 0.0000 \\
\hline MC & 0.001299 & 0.000451 & 2.880662 & 0.0047 \\
\hline$R^{2}$ & 0.749298 & \multicolumn{2}{|c|}{ Media de variable dependiente } & 0.075967 \\
\hline$R^{2}$ ajustada & 0.740578 & \multicolumn{2}{|c|}{ Desviación estándar de var. dep. } & 0.060129 \\
\hline Error est. de regresión & 0.030626 & \multicolumn{2}{|l|}{ Criterio de Akaike } & -4.093177 \\
\hline Suma residuos cuad. & 0.107863 & \multicolumn{2}{|l|}{ Criterio de Schwarz } & -3.977031 \\
\hline Log verosimilitud & 250.5906 & \multicolumn{2}{|l|}{ Estadistico $F$} & 85.92784 \\
\hline Durbin-Watson & 0.895464 & \multicolumn{2}{|c|}{ Probabilidad (estadístico F) } & 0.000000 \\
\hline
\end{tabular}

\begin{tabular}{|c|c|c|c|c|}
\hline \multicolumn{5}{|c|}{ D. Bancos muy pequeños } \\
\hline \multicolumn{2}{|c|}{ Variable dependiente: ROE } & \multicolumn{3}{|c|}{\begin{tabular}{l|l} 
& Muestra: $2002012009 Q 2$ \\
\end{tabular}} \\
\hline \multicolumn{2}{|c|}{ Método: Mínimos cuadrados en panel } & \multicolumn{2}{|c|}{ Secciones - cruzadas: 11} & \\
\hline \multicolumn{5}{|c|}{ Total de observaciones del panel (balanceado): 330} \\
\hline Variable & Coeficiente & Error estándar & Estadístico $t$ & Probabilidad \\
\hline MNI & -0.686783 & 0.228484 & -3.005826 & 0.0029 \\
\hline MNO & 0.047534 & 0.012171 & 3.905543 & 0.0001 \\
\hline MU & 0.003413 & 0.000856 & 3.988894 & 0.0001 \\
\hline RA & 1.894031 & 0.202158 & 9.369059 & 0.0000 \\
\hline$M C$ & 0.001145 & 0.000370 & 3.091573 & 0.0022 \\
\hline$R^{2}$ & 0.499368 & \multicolumn{2}{|c|}{ Media de variable dependiente } & 0.054914 \\
\hline$R^{2}$ ajustada & 0.493206 & \multicolumn{2}{|c|}{ Desviación estándar de var. dep. } & 0.084367 \\
\hline Error est. de regresión & 0.060061 & \multicolumn{2}{|l|}{ Criterio de Akaike } & -2.771887 \\
\hline Suma residuos cuad. & 1.172368 & \multicolumn{2}{|l|}{ Criterio de Schwarz } & -2.714325 \\
\hline Log verosimilitud & 462.3613 & \multicolumn{2}{|l|}{ Estadístico $\mathrm{F}$} & 81.04477 \\
\hline Durbin-Watson & 1.086770 & \multicolumn{2}{|c|}{ Probabilidad (estadistico F) } & 0.000000 \\
\hline
\end{tabular}

Elaboración propia.

Los resultados muestran que el $R O E$ es mejor explicado por las variables seleccionadas en el caso de los bancos medianos y pequeños (y escasamente en los bancos muy pequeños); los bancos grandes son muy distintos del resto, principalmente porque el multiplicador de capital y la rotación de activos muestra una relación negativa con la rentabilidad.

\section{Desaarrollo}




\section{Conclusiones}

En esta investigación se analizó la estructura de la banca comercial con actividades en México en los años recientes, así como los indicadores de rentabilidad y eficiencia operativa. Conocer las condiciones de operación de la banca en México es fundamental para comprender las interrelaciones de estas instituciones con el resto de los sectores económicos y para diseñar criterios de regulación.

Entre los resultados relevantes se encuentran:

a) de acuerdo con el Índice Herfindahl-Hirschman, la concentración de la banca comercial en México es moderada, la combinación de los elementos observados durante mediados de la década de 1990 (privatización, crisis bancaria y económica, y entrada de capital extranjero en el sector) propició que en esa época se mantuviera la menor concentración; en la actualidad, a pesar de que

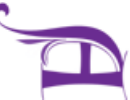
se ha incrementado el número de instituciones, la concentración también es mayor debido a la consolidación de apenas unos cuantos bancos;

b) los bancos más eficientes en la generación de rendimientos son los de mayor tamaño (grandes y medianos);

c) los bancos grandes - cada uno posee más de $15 \%$ del total de activos del mercado- muestran amplias ventajas respecto a los otros, tanto en el margen neto de intereses como en el margen neto de operación;

d) la estructura del margen neto de intereses afecta negativamente el rendimiento sobre capital en casi todos los bancos, con excepción de los mayores;

$e$ ) aunque en promedio el grado de utilización de activos es mayor en los bancos más grandes, éste no es un factor relevante en la explicación de sus rendimientos sobre capital;

f) desde 2008 se aprecia una tendencia al incremento del apalancamiento en todos los bancos, pero los que muestran mayor apalancamiento son los medianos y los pequeños.

\section{Bibliografía}

Ahmad, Rubi, M. Ariff y Michael Skully, "The determinants of bank capital ratios in a developing economy", Asia-Pacific Financial Markets, vol. 15, núm. 3-4, Nueva York, Springer, diciembre de 2008, pp. 255-272.

Akhigbe, Aigbe y James E. McNulty, "The profit efficiency of small US commercial banks", Journal of Banking \& Finance, vol.
27, núm. 2, Carbondale Illinois, Southern Illinois University, febrero de 2003, pp. 307-325.

Allen, Linda y Anoop Rai, "Operacional efficiency in banking: An international comparison", Journal of Banking \& Finance, vol. 20, núm. 4, Carbondale Illinois, Southern Illinois University, mayo de 1996, pp. 655-672. 
Ampudia, Nora, "Treinta años de política monetaria en México", en Etelberto Ortiz (coord.), Hacia una política monetaria y financiera para el cambio estructural y el crecimiento, México, Plaza y Valdés, 2003, pp. 119-161.

Aspe, Pedro, El camino mexicano de la transformación económica, México, FCE, 1993.

Ávalos, Marco y Fausto Hernández, "Competencia bancaria en México", Documento de trabajo, CEPAL, 2006.

Ballescá, Mónica, "La banca extranjera en América Latina: resultado de su desempeño", Espiral. Estudios sobre Estado y sociedad, vol. 14, núm. 40, Guadalajara, Universidad de Guadalajara, septiembre de 2007, pp. 123-156.

Baltensperger, Ernst, "Economies of scale, firm size, and concentration in banking", Journal of Money, Credit and Banking, vol. 4, núm. 3, Columbus Ohio, The Ohio State University, agosto de 1972, pp. 467-488.

Banco de México, "Historia sintética de la banca en México", Documento de trabajo, México, 2007. 1991.

Informe Anual de 1990, México,

Berger, Allen N., Seth D. Bonime, Daniel M. Covitz y Diana Hancock, "Why are bank profits so persistent? The roles of product market competition, informational opacity, and regional-macroeconomic shocks", Journal of Banking \& Finance, vol. 24, núm. 7, Carbondale Illinois, Southern Illinois University, julio de 2000, pp. 1203-1235.

Berger, Allen y Timothy H. Hannan, "The priceconcentration relationship in banking", The Review of Economics and Statistics, vol. 71, núm. 2, Cambridge Massachusetts, Harvard University, mayo de 1989, pp. 291-299.

Berger, Allen y Loretta J. Mester, "Inside the black box: What explains differences in the efficiencies of financial institutions", Journal of Banking \& Finance, vol. 21, núm. 7, Carbondale Illinois, Southern Illinois University, julio de 1997, pp. 895-947.

Berger, Allen N., John H. Leusner y John J. Mingo, "The efficiency of bank branches", Journal of Monetary Economics, vol. 40, núm. 1, Nueva York, University of Rochester, septiembre de 1997, pp. 141-162.

Boncheva, Antonina, "Los intermediarios financieros en México: posibles escenarios en el marco del TLC", Estudios fronterizos, vol. 1, núm. 1, Baja California Sur, Univer- sidad Autónoma de Baja California, 2000, pp. 169-187.

Boyd, John y Gianni De Nicolo, "The theory of bank risk taking and competition revisited", Journal of Finance, vol. 60, núm. 3, Malden Massachussets, American Finance Association, junio de 1995, pp. 1329-1343.

Castillo, Jesús y José Luis Martínez, "El margen financiero de la banca comercial en México 1995-2005”, Quivera, vol. 9, núm. 2, Toluca, Universidad Autónoma del Estado de México, 2007, pp. 155-170.

Correa, Eugenia, "Fobaproa e IPAB: crisis y ocaso de los bancos mexicanos", en A. Girón y E. Correa (comps.), Crisis y futuro de la banca en México, México, Miguel Ángel Porrúa-IIEc-UNAM, 2002, pp. 67-88.

Correa, Eugenia y Esmeralda Maya, "Expansión de la banca extranjera en México" en A. Girón y E. Correa (comps.), Crisis y futuro de la banca en México, México, Miguel Ángel Porrúa-IIEc-UNAM, 2002, pp. 141-152.

Cotler, Pablo, "El rescate bancario y su impacto sobre la cartera crediticia: el caso de México", Documento de trabajo, México, Universidad Iberoamericana, 2004.

Degryse, Hans y Steven Ongena, "The impact of competition on bank orientation", Journal of Financial Intermediation, vol. 16, núm. 3, Urbana-Champaign Illinois, University of Illinois, julio de 2007, pp. 399424

Evanoff, Douglas y Lewis M. Segal, "Strategic responses to bank regulation: Evidence from HMDA data", Journal of Financial Services Research, vol. 11, núm. 1-2, Nueva York, Springer, febrero de 1997, pp. 6993.

Gilbert, R. Alton, "Bank market structure and competition: A survey", Journal of Money, Credit and Banking, vol. 16, núm. 4, Columbus Ohio, The Ohio State University, noviembre de 1984, pp. 617-660.

Girón, Alicia, "La banca mexicana en transición: crisis o reestructuración", en A. Girón y E. Correa (comps.), Crisis y futuro de la banca en México, México, Miguel Ángel Porrúa-IIEc-UNAM, 2002, pp. 47-65.

Girón, Alicia y Eugenia Correa, "Desregulación y crisis financieras" en A. Girón y E. Correa (coords.), Economía financiera contemporánea, Tomo I, México, UNAMPorrúa-UAM, 2004. 
Hannan, Timothy H., "Market share inequality, the number of competitors, and the $\mathrm{HHI}$ : An examination of bank pricing", Review of Industrial Organization, vol. 12, núm. 1, Nueva York, Springer, febrero de 1997, pp. 23-35.

"Foundations of the structure-conducte-performance paradigm in banking", Journal of Money, Credit and Banking, vol. 23, núm. 1, Columbus Ohio, The Ohio State University, febrero de 1991, pp. 68-84.

Hannan, Timothy H. y Robin A. Prager, "The profitability of a small single-market banks in an era of multi-market banking", Journal of Banking \& Finance, vol. 33, núm. 2, Carbondale Illinois, Southern Illinois University, febrero de 2009, pp. 263-271.

Koskela, Erkki y Rune Stenbacka, "Is there a tradeoff between bank competition and financial fragility?", Journal of Banking \& Finance, vol. 24, núm. 12, Carbondale Illinois, Southern Illinois University, diciembre de 2000, pp. 1853-1873.

Koutsomanoli-Filippaki, Anastasia, Emmanuel Mamatzakis y Christos Staikouras, "Structural reforms and banking efficiency in the New EU States", Journal of Policy Modeling, vol. 31, núm. 1, Rhode-Saint-Genèse, Society for Policy Modeling, enero-febrero de 2009, pp. 17-21.

Liang, Nellie, "Bank profits, risk, and local market concentration", Journal of Economics and Business, vol. 41, núm. 4, Philadelphia, Temple University, noviembre de 1989, pp. 297-305.

Luo, Xueming, "Evaluating the profitability and marketability efficiency of large banks. An application of data envelopment analysis", Journal of Business Research, vol. 56, núm. 8, agosto de 2003, pp. 627-635.

Mester, Loretta J., L. I. Nakamura y M. Renault, "Checking accounts and bank monitoring", Working Paper, núm. 98-25, Filadelfia, Federal Reserve Bank of Philadelphia, 1998.

Murillo, José A. "La banca en México: privatización, crisis y reordenamiento", Documento de trabajo, México, Banco de México, 2002.
Núñez, Héctor, Reforma y crisis del sistema bancario 1990-2000, México, Plaza y Valdés, 2005.

Petersen, M. A. y R. G. Rajan, "The effect of credit market competition on lending relationships", Quarterly Journal of Economics, vol. 110, núm. 2, Cambridge Mass., Harvard University, mayo de 1995, pp. 407-443.

Pilloff, Steven J. y Stephen A. Rhoades, "Structure and profitability in banking markets", Review of Industrial Organization, vol. 20, núm. 1, Nueva York, Springer, febrero de 2002, pp. 81-98.

Pineda, Pablo, "El perfil de la banca comercial en México al final de la administración zedillista”, Espiral. Estudios sobre Estado y sociedad, vol. 9, núm. 26, Guadalajara, Universidad de Guadalajara, septiembre de 2003, pp. 29-64.

Rose, Peter y Sylvia C. Hudgins, Bank Management \& Financial Services, Nueva York, Mc Graw Hill, 2008.

Shaffer, Sherrill, "Patterns of competition in banking", Journal of Economics and Business, vol. 56, núm. 4, Filadelfia, Temple University, julio-agosto de 2004, pp. 287-313.

Watt, Richard y Javier De Quinto, "Some simple graphical interpretations of the HerfindahlHirschman Index and their implications", Documento de trabajo, núm. 1, Madrid, Instituto Universitario de Estudios Europeos de la Universidad San Pablo, 2003.

Williams, Barry, "Domestic and international determinants of bank profits: Foreign banks in Australia", Journal of Banking \& Finance, vol. 27, núm. 6, Carbondale Illinois, Southern Illinois University, junio de 2003, pp. 1185-1210.

Zarruk, Emilio y Jeff Madura, "Optimal bank interest margin under capital regulation and deposit insurance", The Journal of Financial and Quantitative Analysis, vol. 27, núm. 1, Seattle, Washington, University of Washington, marzo de 1992, pp. 143-149. 
Anexo 1

Para evaluar la concentración del mercado es útil calcular el Índice Herfindahl-Hirschman (HHI). Éste se calculó a partir de:

$$
H H I=\sum_{i=1}^{n} S_{i}^{2}
$$

Donde $s_{i}$ representa la participación de cada institución $i$ en el mercado. Para cada fecha comprobamos que obtenemos idénticos resultados si utilizamos la descomposición de este indicador sugerida en Hannan (1997) y en Watt y De Quinto (2003); es decir, definiendo la participación promedio en el mercado como:

$$
\bar{s}=\frac{1}{n},
$$

Donde $n$ es el número de firmas participantes, y dado que la varianza de la participación de cada firma en el mercado se define como:

$$
\begin{aligned}
& v(s)=\frac{\sum_{i}(s i-\bar{s})^{2}}{n-1} \\
& v(s)=\frac{\sum_{i}\left(s_{i}^{2}-2 s_{i} \bar{s}+\bar{s}^{2}\right)^{2}}{n-1}=\frac{\sum_{i} s_{i}^{2}-2 \bar{s} \sum_{i} s_{i}+\sum_{i} s_{i}^{2}}{n-1}
\end{aligned}
$$

Dado que:

$$
\begin{aligned}
& \sum_{i} s_{i}=1, \quad \text { y } \quad \sum_{i} s_{i}^{2}=n \frac{1}{n^{2}}=\frac{1}{n}, \text { entonces: } \\
& v(s)=\frac{H H I-2 \bar{s}+\bar{s}}{n-1}=\frac{H H I-\bar{s}}{n-1} \\
& H H I=(n-1) v(s)+\bar{s}
\end{aligned}
$$

Como se aprecia de la ecuación (A.4), el incremento en la varianza de las participaciones de las firmas en el mercado aumenta el $H H I$, mientras que el incremento en el número de observaciones lo reduce. Este hecho es relevante en la evaluación de la concentración del sistema bancario comercial en México, donde tradicionalmente una tercera parte de las instituciones (integradas por los bancos grandes, medianos y pequeños) abarcan más de $80 \%$ del mercado. Por esta observación, se realizó una modificación de la razón de concentración $C R$ (y del propio $H H I$ ); tradicionalmente la tasa de concentración se calcula como: 


$$
C R=\sum_{j=1}^{k} s_{j}
$$

Donde sólo se considera la participación en el mercado de las firmas de mayor tamaño, las que son elegidas arbitrariamente. En su lugar, en la investigación se utiliza la Razón de Concentración Modificada $(M C R)$ :

$$
M C R=\sum_{j=1}^{k} s_{j}^{2}
$$

Este indicador es similar al $H H I$, pero sólo incluye a las instituciones de mayor tamaño, para eliminar el sesgo ocasionado por la inclusión de las firmas muy pequeñas. Para la estimación de (A.6) se hicieron dos cálculos, en el primero de ellos $M C R 1$, se consideraron los bancos grandes, medianos y pequeños, es decir, los que poseen más

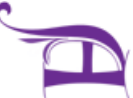
de $1 \%$ de los activos en cada fecha; en el cálculo $M C R 2$, se consideraron los bancos grandes y medianos.

Es importante destacar que el $H H I$ mostró resultados de concentración moderada entre 0.128854 y 0.162228 , y concentración promedio de 0.147173 ; para este indicador hay una evidente relación contraria entre el número de bancos y la varianza de las participaciones en el mercado, esto se corrobora con el coeficiente de correlación entre ambas variables, $\rho\left(n, \sigma^{2}\right)$ que es de -0.951636 . Al considerar el indicador $M C R 1$, la concentración fluctuó entre 0.146585 y 0.183114 , con valor promedio de 0.166788 ; en este caso el coeficiente de correlación es -0.714474. Por último, en el indicador $M C R 2$, que sólo incluye los bancos grandes y medianos, la concentración varía entre 0.184216 y 0.227777 , con promedio de 0.209682 ; lo interesante de este indicador es que ahora el número de observaciones y la varianza de las participaciones en el mercado tienen escasa vinculación, aquí el coeficiente de correlación es de 0.541714 . Debe observarse también que en cualquiera de los casos, la concentración de la banca comercial en México no parece seguir un patrón de variación en el tiempo. 
Cuadro A1

Indicadores de concentración de la banca comercial en México

\begin{tabular}{|c|c|c|c|c|c|c|c|c|c|}
\hline Fecha & HHI & $n$ & $\sigma^{2}$ & MCRI & $n$ & $\sigma^{2}$ & MCR2 & $n$ & $\sigma^{2}$ \\
\hline jun-01 & 0.143575 & 34 & 0.003459 & 0.165042 & 10 & 0.007227 & 0.202101 & 7 & 0.009874 \\
\hline sep-01 & 143284 & 33 & 0.003531 & .161684 & 11 & 0.007077 & 0.184216 & 8 & 0.008459 \\
\hline dic-0l & 162229 & 31 & 0.004332 & 0.182886 & 10 & 0.009210 & 0.204373 & 7 & 0.010253 \\
\hline mar-02 & 0.155809 & 31 & 0.004118 & 0.174408 & 10 & 0.008268 & 0.197410 & 7 & 0.009092 \\
\hline jun-02 & 153195 & 31 & 0.004031 & 0.173033 & 10 & 0.008115 & 0.215465 & & 0.009760 \\
\hline sep-02 & 146373 & 32 & 0.003714 & 0.165136 & 10 & 0.007237 & 0.189684 & 7 & 0.007804 \\
\hline dic-02 & 0.161144 & 33 & 0.004089 & 0.183114 & 9 & 0.009000 & 0.221103 & 6 & 0.010887 \\
\hline mar-03 & 0.159541 & 33 & 0.004039 & 0.180276 & 10 & 0.008920 & 0.206289 & 7 & 0.010572 \\
\hline jun-03 & 157703 & 32 & 0.004079 & 0.182179 & 9 & 0.008883 & 0.224152 & 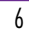 & 0.011497 \\
\hline sep-03 & 0.149715 & 32 & 0.003821 & 0.170822 & 11 & 0.007991 & 0.197885 & 7 & 0.009171 \\
\hline dic-03 & 0.151673 & 32 & 0.003885 & 0.176782 & 9 & 0.008209 & 0.197208 & 7 & 0.009058 \\
\hline mar-04 & 145099 & 32 & 0.003673 & 0.165596 & 11 & 0.007469 & 0.214691 & 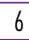 & 0.009605 \\
\hline jun-04 & 0.147357 & 32 & 0.003745 & 0.169014 & 11 & 0.007810 & 0.217258 & 6 & 0.010118 \\
\hline sep-04 & 0.140889 & 32 & 0.003537 & 0.163227 & 10 & 0.007025 & 0.207409 & 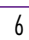 & 0.008148 \\
\hline dic-04 & 150947 & 30 & 0.004056 & 0.165701 & 12 & 0.007488 & 0.221512 & & 0.010969 \\
\hline mar-05 & 0.152696 & 29 & 0.004222 & 0.167049 & 12 & 0.007611 & 0.209647 & 6 & 0.008596 \\
\hline jun-05 & 0.152491 & 29 & 0.004215 & 0.169285 & 11 & 0.007838 & 0.205350 & 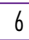 & 0.007737 \\
\hline sep-05 & 152568 & 29 & 0.004217 & 0.166447 & 12 & 0.007556 & 0.208268 & & 0.008320 \\
\hline dic-05 & 0.153004 & 29 & 0.004233 & 0.168558 & 11 & 0.007765 & 0.203926 & 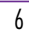 & 0.007452 \\
\hline mar-06 & 0.145703 & 29 & 0.003972 & 0.163999 & 11 & 0.007309 & 0.201342 & 6 & 0.006935 \\
\hline jun-06 & 0.145761 & 30 & 0.003877 & 0.163438 & 11 & 0.007253 & 0.201385 & 6 & 0.006944 \\
\hline sep-06 & 0.150291 & 31 & 0.003934 & 0.171632 & 10 & 0.007959 & 0.204908 & 6 & 0.007648 \\
\hline dic-06 & 0.147519 & 31 & 0.003842 & 0.164989 & 11 & 0.007408 & 0.226396 & 5 & 0.006599 \\
\hline mar-07 & 0.144865 & 35 & 0.003420 & 0.162636 & 12 & 0.007209 & 0.204483 & 6 & 0.007563 \\
\hline jun-07 & 0.142781 & 39 & 0.003083 & 0.164237 & 11 & 0.007333 & 0.203679 & 6 & 0.007403 \\
\hline sep-07 & 0.142611 & 39 & 0.003078 & 0.164563 & 11 & 0.007365 & 0.227777 & 5 & 0.006944 \\
\hline dic-07 & 0.141024 & 40 & 0.002975 & 0.160262 & 12 & 0.006994 & 0.225529 & 5 & 0.006382 \\
\hline mar -08 & 0.136508 & 40 & 0.002859 & 0.154802 & 13 & 0.006490 & 0.224803 & 5 & 0.006201 \\
\hline jun-08 & 0.128855 & 42 & 0.002562 & 0.146585 & 13 & 0.005805 & 0.196680 & 0 & 0.006003 \\
\hline sep-08 & 0.129621 & 43 & 0.002533 & 0.154046 & 11 & 0.006314 & 0.198445 & 6 & 0.006356 \\
\hline dic-08 & 0.141152 & 43 & 0.002807 & 0.160854 & 12 & 0.007047 & 0.223196 & 0 & 0.005799 \\
\hline mar-09 & 0.138682 & 43 & 0.002748 & 0.160708 & 12 & 0.007034 & 0.225729 & 5 & 0.006432 \\
\hline jun-09 & 0.142058 & 43 & 0.002829 & 0.161035 & 13 & 0.007009 & 0.227206 & 5 & 0.006801 \\
\hline
\end{tabular}

Nota: $\mathrm{El}$ indicador $\mathrm{HHI}$ incluye todos los bancos existentes, $\mathrm{MCR}$ I incluye los bancos con el $1 \%$ o más de los activos y MCR2 incluye los bancos con el $5 \%$ o más de los activos. En cada caso, la columna $n$ indica el número de bancos considerados y la columna $\sigma^{2}$ indica la varianza de las participaciones en el mercado.

Fuente: Elaboración propia.

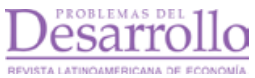




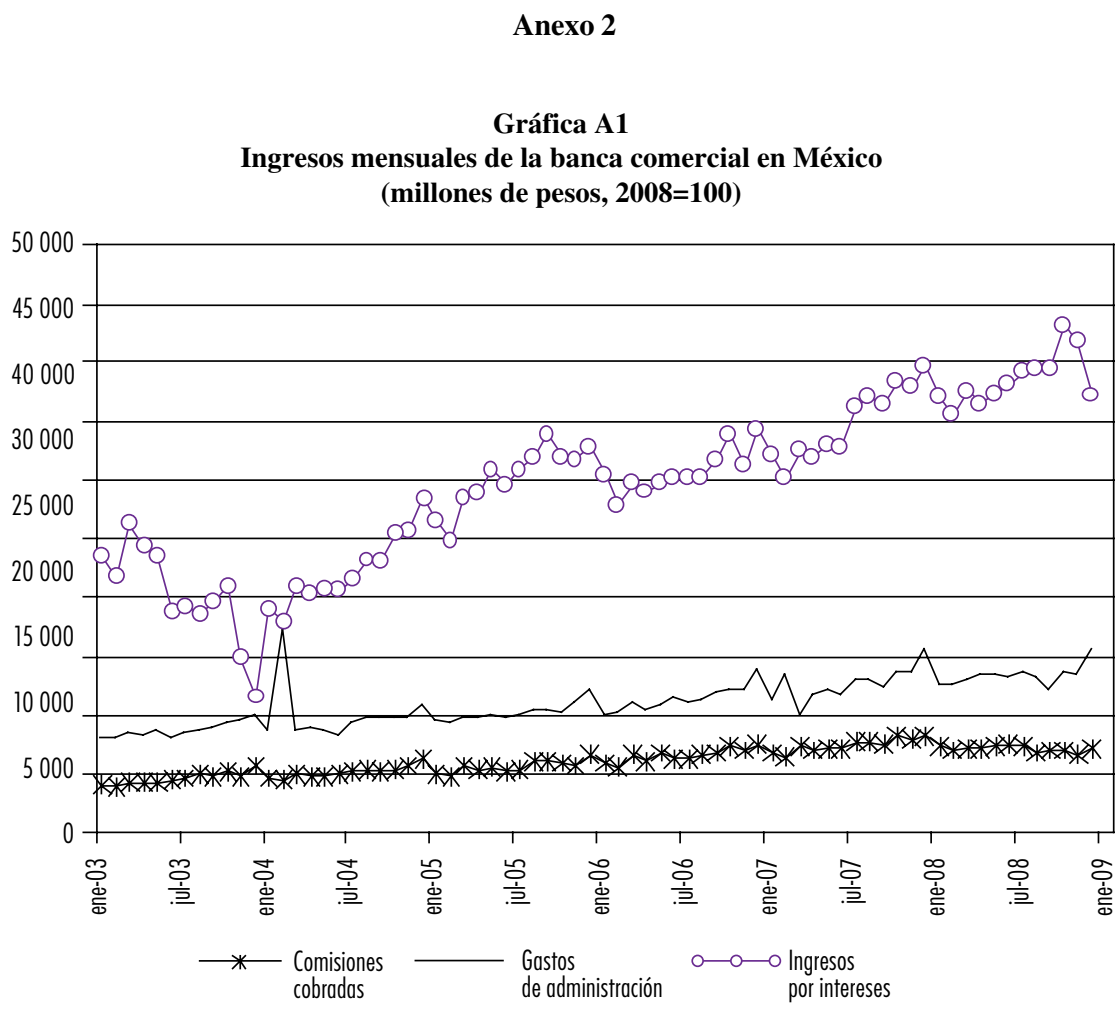

Fuente: Elaboración propia con base en información de la Comisión Nacional Bancaria y de Valores. 